\title{
Recently Identified University Students Navigate Dyslexia
}

\section{Introduction}

A number of models of disability inform how dyslexia is understood. Dominant amongst these in the UK are the medical and social models. In the simplest terms, the medical model suggests that there is a need to diminish the disabling nature of dyslexia (Goodley, 2017) whilst the social model suggests that the environment should be adapted (Macdonald, 2009). Jamieson and Morgan (2008) further indicate that the medicalisation of dyslexia as a disability is a means to an end to ensure funding for support is secured. In contrast, the idea that the sociological "ambivalence of labelling as developed in a prominent theory of medicalisation" suggests that dyslexia can be viewed as a sickness which requires help seeking (Solvang, 2007, p.81). Both the medical and social models exclude a focus on the needs, experiences and perceptions of the individual with dyslexia. In contrast, this research has adopted an affirmation model of disability, acknowledging "a non-tragic view of disability and impairment which encompasses positive social identities, both individual and collective, for disabled people" (Swain and French, 2000, p.569). More specifically, for this paper, affirmation of dyslexia acknowledges that an identity has been accepted and that each individual delineates their parameters of dyslexia as informed by experience, reflection and self-study.

A key challenge when researching dyslexia is the notion that there is no one universally agreed definition (Henderson, 2017; Jensen, 2010). Consequently, researchers often seek to clarify and impose meaning on the word, arguably at the expense of seeking meaning from individuals who experience it. There are many definitions within the public domain (Reid, 2016; Brunswick, 2012) which emphasise a deficit component of dyslexia. For the purposes of this research, dyslexia is understood as a specific learning difficulty "that is neurobiological in origin...characterized by difficulties that [are] often unexpected in relation to other cognitive abilities and the provision of" structured education (IDA, 2002; Dickman, 2017). However, recent thought within the field seeks to consider how individuals with dyslexia understand their own experiences and have begun to form a foundation for an arguably more balanced approach to exploring concepts of a dyslexic identity (Burden, 2005; Eide, 2016). It is not within the scope of this article to further debate the nuances that inform how definitions of dyslexia are reached. Instead, this research sought to better understand how students define, understand and apply meaning to their dyslexia identities. This study investigated the experiences of learners with dyslexia who were identified at university and how this impacted on their understanding of their learning and identities. Specifically, the nature of identity was considered in relation to social identity theory, labelling and self-understanding of dyslexia. 


\section{Literature Review and Theoretical Background}

Whilst it is important to acknowledge that an extensive number of issues contribute to social constructs of identity and disclosure of dyslexia, the scope of this research does not allow for a comprehensive investigation of these issues. In this study, a number of key theories underpinned the exploration including: social identity theory; labelling theory; and dyslexia identity.

\section{Social Identity Theory}

Within higher education, students with dyslexia are grouped categorically with all students who have a specific learning difficulty (Pino and Mortari, 2014). Although institutionally students are reported on in a homogenous construct, it is unclear as to whether or not students align with this imposed identity. Social identity theory posits that a person understands who they are based on their relationships with others who share a group membership. More specifically Tajfel (1978) advocated that identity is aligned with social groups. In contrast, Deaux (1993) suggests that there is scope for social identities and personal identities to intersect because identities can shift in different contexts. Jenkins (2014, p.204) echoes the complexity of social identities by acknowledging that there are connections between "individual and collective identity [which] are as much an interactional product of 'external' identification by others, as they are of 'internal' self-identification."

Considering dyslexia and social identity theory is further complicated as students themselves are not visually identifiable by any consistently distinctive or identifying features (Nalavany, Carawan, and Sauber, 2013) and are thus considered to have invisible disabilities. The construct of a social identity raises questions about belonging, discrimination and barriers for students with dyslexia within the university context.

\section{A Dyslexic Identity?}

Differentiating between identity typologies can prove challenging, both in a sociological context and in terms of how students understand their own sense of self. Burden (2005) articulates that there are a variety of considerations that may contribute to a student's ability to understand a dyslexia identity construction. He notes that prior educational attainment, self-efficacy and self-concept are all contributing factors in this process. More recent studies suggest that a positive understanding of self contributes to an improved dyslexic identity that typically results in increased motivation in studies; higher level of engagement with support; greater success in studies; and compensatory strategies resulting in resilience when managing difficulties attributed to dyslexia (Armstrong and Humphrey, 2009). There are also a range of conflicting perceptions of dyslexia in the public domain, which pose challenges for students who are newly assessed and identified at university. The growing literature surrounding the construction of positive dyslexia (West, 2009; Eide and Eide, 2011; Nicholson, 2015; Kannangara, 2015) also generates questions as to whether or 
not dyslexia has become a socially acceptable and even desirable difficulty within student populations. Cameron and Billington (2015) caution that, within university, "being dyslexic can be an escape from accusations of moral and intellectual inferiority which appear still to be connected to people who struggle with particular culturally valued performances like reading, writing, memorising and expressing academic ideas quickly and articulately." Nonetheless, there remains a question as to whether or not dyslexia is a distinctive and solitary identity or if it is best situated within intersecting typologies. Moreover, how students understand their dyslexia as a component of their identities or as a distinct and independent identity has yet to be distinguished in existing literature.

\section{Labelling Theory}

Dyslexia is often referred to as a label (Riddick, 2000; Dale and Taylor, 2001; Solvang, 2007). In an inclusion context, dyslexia labels can pose barriers to activities, interaction and learning opportunities. Labels can contribute to self-fulfilling prophesies and direct the actions of individuals as a consequence of the labels others have applied to a given identity (Boyle, 2013). Labelling does not necessarily automatically result in negative perceptions or behaviours. For example, Weinstein (2002) suggests the possibility of and importance of reframing labels in order to socially construct an alternative narrative in the field of disability. In the case of dyslexia, some researchers suggest that the label of dyslexia can contribute to stigmatisation and isolation; whilst others query whether or not the label results in delayed disclosure at university (Henderson, 2017). However, the notion of labelling as a means of providing university students with a starting point to name and contextualise the specific nature of their individual challenges and strengths can also act as a springboard to facilitate a deeper self-understanding.

\section{Methodology}

\section{Rationale and research questions}

This study sought to investigate the experiences of learners with dyslexia who are identified at university and how this impacts on their understanding of their learning as well as to explore the extent to which dyslexia forms part of identity. Specifically, this study explored the student experience of undergoing a dyslexia assessment; whether or not social identity theory provided a useful framework for understanding how students understood their dyslexia; and if the student-participants felt that they had been labelled as part of the assessment process.

\section{Context and Research Design}

As this research investigated the unique perspectives of learners who had recently been identified with dyslexia at university, the study adopted an interpretative, qualitative, phenomenological case study framework (Denscombe, 2010; Merriam and Tisdell, 2016). Because this study gathered rich descriptions of how students interpret their own 
experiences, it is situated within an interpretive paradigm (Denzin and Lincoln, 2011). The methodological framework for this research illuminated individual student perceptions of the phenomenon of dyslexia identification at university.

\section{Interpretive Phenomenological Analysis}

Interpretative phenomenological analysis (IPA) offered opportunities to evaluate and reflect upon contributions from learners (Smith, Flowers and Larkin, 2009). Additionally, IPA allowed insight into how the participants interpreted their individual understandings of their social and personal worlds (Smith and Osborn, 2008). Epistemologically, this research did not seek one single truth; rather, it acknowledged the value and validity in multiple truths informed by experiences. Furthermore, this research celebrated the multiplicity within these perspectives and "accept[ed] the diversity and plurality of the world, no one element is more powerful than another" (Merriam and Tisdell, 2016). Ultimately, a dialogical approach within a phenomenological framework acknowledged the limitations of a socially constructed reality of dyslexia. Relationships not only contributed to the trustworthiness of the data gathered, but also to the credibility of the student perspectives (Denzin and Lincoln, 2011).

\section{Sample}

Eight university students from across the university were purposively selected as they had recently been identified with dyslexia. All student-participants were enrolled in a single small UK university. Students ranged in age from 21 to 52 years old. Two were male and six were female. Questions were explored to determine whether or not individuals perceived themselves as part of a cohesive group with a shared identity. The research focused on gaining a better understanding of their unique and individual experiences and perceptions of their individual dyslexias.

\section{Methods}

Three methods of data collection, a qualitative questionnaire, semi-structured interviews and construction of a personal artefact of dyslexia, contributed to the reliability of the research. Questionnaires were used to purposefully select learners who were invited to participate in a semi-structured interview. Semi-structured interviews allowed the research to probe learners to express, in descriptive detail, individual perspectives about dyslexia at university (Drever, 2006). Students were asked to represent their own concepts of dyslexia as it has developed whilst at university through individual 'self-portraits' or artefacts (Mitchell, Pithouse and Molesane, 2009). They were each provided with a broad range of paint, drawing and crafting resources to create their artefacts. The intension behind providing diverse resources was to foster maximum flexibility in the creation of an artefact that best represented how students experienced and understood their dyslexia. Artefacts, within this social research provided a contextual basis and a multisensory experience for 
participants, which afforded an additional modality to frame how they could represent, describe and reflect on their dyslexia (Kara, 2015; Norum, 2008; McLoughlin and Leather, 2013). Moreover, there is a growing body of literature that suggests that individuals with dyslexia think differently, creatively and that this is thinking that warrants alternative means of expression to capture the essence of their thoughts (Shaywitz, 2003; Leveroy, 2013; Eide and Eide, 2011). There was no time limit imposed and students were offered the opportunity to take materials home if they wished to create their artefact outside of university. Only one individual chose to do this. Interviews and narratives about their individual artefacts were recorded, transcribed and stored securely. Triangulation allowed the research to consider the emerging themes that capture learner perspectives through different methods which were member checked, increasing validity (Creswell, 2014).

\section{Ethical Considerations}

Ethical considerations were identified and addressed in order to ensure that participants voluntarily consented to participation in this study (BERA, 2011). Additionally, pseudonyms were assigned to protect confidentiality of the student-participants. Each potential participant was individually informed about the aims of the research, the nature of their participation and how findings would be distributed. Students were initially informed about the study via email, so that, if desired, they could use text readers to support them to access text on the information sheet and informed consent document. This approach further facilitated transparency and ensured clarity of how data was used within the study, minimising risks for potential misunderstandings (Savin-Baden and Major, 2013).

\section{Findings and Discussion}

Five core themes emerged from the research. IPA was applied when reviewing how students understood the phenomenon of being identified with dyslexia whilst at university. This ideographic focus supported students to use artefacts as a means of expression of experience and complemented dialogical engagement when students were asked to reflect on how they understood their dyslexia. Students made specific reference to their artefacts when they spoke about their journeys to identification, explaining how an aspect of the artefact represented a particular element of their understanding of their dyslexia; some also referred to earlier educational experiences and conversations about dyslexia. They expressed how having an identification intersected with their broader understanding of self. Students did not express a connection to the concept of a shared identity, aligned with social identity theory (Tajfel, 1978). Instead they suggested that they felt dyslexia was an intersecting component of their individual identities as articulated by Deaux (1993) and Jenkins (2014). Finally, whilst labelling featured, most students discussed broader approaches to inclusive teaching to enhance learning experiences rather than a sense that they were defined by others' perceptions of dyslexia. This reframing of the idea of labelling as a means of naming a series of described experiences tended to be viewed positively by the participants and reflected Weinstein's (2002) suggestion that labels can be reframed. 


\section{Referral and Assessment Journey}

Students' individual journeys and reflective understandings of prior learning incidents revealed that the path to discovering they had dyslexia was a very personal and illuminating experience. The majority of students self-referred for screening and assessment of dyslexia. However, Callum (M.A., First Year) explained:

"I'd done a dyslexia test only to respect a lecturer who suggested that I go and take the test. I certainly didn't feel that there was any need for me to do so...so when I done the test, it turns out that I was dyslexic and even then I didn't really believe it."

Callum's perceptions of dyslexia were informed by societal misconceptions, which, for him, meant that spelling, reading, writing and achieving were likely to be inconsistent at best and that there were greater instances of failure if dyslexic. Therefore, initially, he rejected a dyslexia identification.

Paul (B.A., Final Year) reflected on prior learning experiences in response to discovering he had dyslexia. He provided examples of incidents in school and the impact of these experiences on learning. Paul remarked,

"I've only been diagnosed with it in the last four years. Knowing it just confirmed my suspicion because I've always struggled with the written word and reading.... It's held me back really, because it affected my self-confidence definitely when I was younger because I was perceived as lazy, or stupid...."

Paul indicated that not being identified when he was younger, upon reflection, was damaging not only to his academic progression, but also to his sense of self. This realisation was both affirming and disabling simultaneously.

Sarah (B.A., Final Year) indicated that she was reassured. She explained,

"When I first had the result of the assessment, I actually cried, but that was a sense of relief, because I thought that there was something that I couldn't explain and that explained it."

The concepts of uncertainty and the impact of not knowing whether or not dyslexia is the explanation for difficulties were echoed by Kirsty (B.Sc., First Year),

“...it was never really picked up in school...I don't think it defines me at all,...I thought I was being lazy, I thought I was being unmotivated. I kind of drilled into my head that I expected the best of myself, but I didn't want to work for it."

Kirsty presents an interesting contrast to other student-participants' understandings of their dyslexias. Rather than recounting how others viewed her, particularly in a negative light, she had been self-critical by describing herself as lazy. 


\section{Dyslexic Identity and Self-Understanding}

Student-participants consistently highlighted the concept of difference when describing how they perceived their dyslexia and how they understood what it meant for them individually. It is relevant to note that they described and defined dyslexia in terms of their own experiences rather than providing a generalised concept of dyslexia. Callum elucidated,

"It's a different way of thinking... that the mind functions in a slightly different way, where the information is processed differently and so for me I see it that dyslexia is a benefit, because it allows me to think more broadly about any issue."

Becky (M.A., First Year) expounded,

“...for my personal definition of dyslexia, it's about the memory. I just can't remember things...."

Sarah elaborated,

"I would say that it's, um, a different way of learning...that some people with dyslexia have an issue with their memory, which is the case for myself, around my working memory, being able to recall and retain information...."

Becky and Sarah attribute difference to working memory difficulties. However, despite identifying some specific difficulties that Sarah associates with her dyslexia, she poignantly explained,

"I don't personally see it as a disability, actually, since being assessed...I see it as a strength and for me it explains sometimes why I may take longer to do certain things, but also my thought process."

Despite having undergone an induction appointment and discussing the nature of dyslexia as well as how it could be observed in Maxine's (M.A., Final Year) assessment results, she was less confident that she had received a thorough explanation of her dyslexia,

“...it's never really been explained to me. I've just gone through the system and been told that I've got dyslexia. So, dyslexia to me...it's disorganisation, obviously you hear that it's got to do with reading, but I don't have that problem, so that's not dyslexia to me...sequencing? Yeah, that's what it is to me...it's just taking its time to click in."

Her understanding suggested that several unanswered questions about her dyslexia persist and that she has not yet settled on a particular set of descriptors to adequately describe her dyslexia. This confusion and ongoing journey were also reflected in the Maxine's artefact, which she explained, 
"I've put on here, 'What is dyslexia', just simply because it's so broad...I don't think that question can really be answered...."

Donna (M.A., First Year) felt that she had,

"an emotional response to it, so I feel quite...attached to that word now. It represents, quite a lot of negative experiences for me, some positive ones too, but to the larger extent, when I think about it over my life course, certainly, a lot of negative connotations."

The feeling of exclusion and negativity around how students came to understand that they had dyslexia was further articulated by Becky, who explained,

"I feel different. I feel excluded. I think I have a really, a really unfortunate memory that comes to mind of being probably seven and being called a cabbage by the teacher. I kinda feel like, even now, what is happening for me is that...my mind is going in lots of different directions and I'm struggling to remember what you asked me."

Donna and Becky also reflected on the isolating educational experiences they had previously. Their journeys to discovering dyslexia were not only longer, but also involved ongoing reflection on the barriers and challenges faced and, in many ways overcame, to persevere to a higher level of academic study. The concept of struggle is reinforced by Kirsty

"Pain! Pain! That's what it is. Um, especially, with being at uni, it's definitely been a massive strain, but it's a strain that I've always kind of felt, but I thought that it was for other reasons, I thought I was just being quite lazy and there was just something wrong with me...."

\section{Too Many Ideas!}

Interestingly, after most students created their artefacts, their descriptions of their dyslexia shifted from deficits, to descriptions of challenges. Becky created a tangible wall from clay and a tangled ball of pipe cleaners, rubber bands and other materials and explained,

"Well, that is the wall that I feel that comes up and blocks my mind and that's just all things that are going on. Um, I feel like, almost, there's just too much going on in my head, that's just trying to separate it, but you can't and it just feels like the information sort of gets overloaded and it just, I'm trying to process and think about it but then a wall just goes down, and sometimes I get a mind blank."

A similar feeling of struggling with a wash of ideas and difficulty separating the interesting from the relevant was expressed by Sarah who, when reviewing her artefact, explained,

"I just see it as everything intertwining, every area of your life and then the developmental side, everything." 
The idea that everything was connected was a common theme in the artefact descriptions; however, Callum (M.A., First Year) elaborated on the challenge of trying to locate and manage information by expressing that,

"the key thing about the dyslexia for me is that I feel that everything is at arm's length. ...there's an idea in my head and yet to express it in whichever way...it's just not quite easy, easily got at. It's quite difficult. But I see those ideas are there, you know and there's some confidence within I think because I'm quite sure about those ideas, and it's all about trying to learn how I, how I grasp these ideas."

The notion of interconnected ideas is further described by Paul who stated,

"I would also say that my dyslexia, it's...I never have had a linear train of thought. Um, so when I start thinking about things, it's very hard for me to focus on a specific thing, because it leads me to think about other things that the more I think about it, the further away from the initial thing I move."

\section{Social Identity Theory Rejected}

Despite the institutional and national categories that capture and contain students with dyslexia under the umbrella term, specific learning difficulty, student-participants in this research did not mention a dyslexia identity. Dyslexia was understood as an individual rather than a shared or social group experience. Callum explained,

"You know, I sat down with dyslexic support workers and read a few texts and spoke to all the students who are dyslexic and still couldn't tie myself into that group...spoke about it and I sort of felt that I understood myself a little more, so, from then on I wanted to learn more about dyslexia and I started to believe that I was dyslexic."

Callum's self-understanding required dialogical engagement with a dyslexia support specialist; however, it is notable that his understanding did not result in his desire to seek out other students with dyslexia. For him, his increased understanding was largely an independent endeavour which he pursued through further study.

Dyslexia as a social identity was also rejected by other students who felt comfortable that whilst dyslexia comprised a part of their identity, it did not prompt them to construct a social group based on the shared identity of dyslexia. Paul indicated that he knew other students with dyslexia on his course,

"But it's not like we then specifically go out of our way to just solely work with each other, because we work with anyone."

The idea that dyslexia would be a thread to inform group connections was also rejected by Sarah who confirmed, 
"I see it positively...I wouldn't say it's who I am, but it makes up part of who I am...I wouldn't say it's the dyslexia that makes us work together...I wouldn't say it's dyslexia that makes connections."

Becky (M.A., First Year) suggested that university students with dyslexia may share some similar characteristics, but indicated that she had not explored this idea. She speculated that she would be interested to speak with others and ask,

"Is our sort of dyslexia the same? Is there is a sort of a universal feeling towards it all, a universal way of dealing with it? It's interesting to compare as well...would be nice one day just to sit down with a group of people that have got dyslexia...."

She felt that the opportunity to meet as a group may result in a different understanding of dyslexia for her. There are additional questions regarding the nature of identity that need to be explored here as the institutional structure, confidentiality requirements and government funding restrictions may be unspoken factors that contribute to why students do not describe themselves as part of a group of university students with dyslexia.

\section{Inclusive Learning and Labels}

Most students did not consider dyslexia to be a label and instead described it as a part of themselves, an identity, a difference or a need. Self-understanding of dyslexia remained a touchstone when students explored possible methods of improving institutional understanding of dyslexia and reasonable adjustments to enhance inclusive practice. Students also reframed dyslexia again when they spoke about how they might discuss it with others. Callum suggested,

"I feel that learning, it should come in different forms...it certainly should be varied, Formatted: Space After: $0 \mathrm{pt}$ and therefore shouldn't be tailored necessarily to wholly suit dyslexic people. Dyslexic people should be challenged, it's part of dyslexia I think. I find that I work best when I am challenged...."

Paul (B.A., Final Year) also rejected the notion of the need to label students with dyslexia and highlighted his particular strengths and how he uses these to inclusively access information through self-advocacy in lectures.

"As an adult, and actually knowing that I have dyslexia...it just sort of confirmed my suspicion that I'm not dumb, that I'm not all those titles, you know...if I don't understand...then I'll open up my big mouth and articulate that...."

In contrast, however, Donna found comfort in her identification of dyslexia, but indicated that a label acted as a springboard for transparent conversation, stating, 
"I don't believe it should be stigmatised and so, having done well and been relatively well thought of by colleagues, I felt that it was an honest and, uh progressive thing to do, in identifying with the label."

Sarah (B.A., Final Year) also embraced the concept of a label and explained, "I don't see us as being different, just that we think differently, but other people that don't have dyslexia think differently anyway. I guess we just have a label to explain our difference."

Sarah further elaborated that the label of dyslexia could improve inclusive practice, pointing out that improving inclusion required communication with lecturers,

"I think, sharing the fact that you have dyslexia helps to make it inclusive in terms of telling your lecturers, being open and honest about what specifically your issue is...."

Rita (B.A., Second Year) echoed the need for improved communication; however, indicated that she had taken measures to adapt to lectures, but that,

“...lecturer wise, I think...like, lecture notes, maybe print them off before and actually listen to the students,...I get so much more out of the seminar when I write on the lecture slides and I feel more organised and I feel like, that I'm taking more in...."

Maxine expressed that there may be a lack of knowledge about the nature of dyslexia and that working collaboratively with Dyslexia Support Services, who she described as mentors, might improve inclusive practice across the institution. She suggested that,

"a little bit of training with the lecturers and the mentors together would be really good. And for them to actually have a discussion, rather than keeping it separate...so I think it would be really good if they could come together, because essentially, without either one of them, [university studies] wouldn't work for the dyslexic student."

A collaborative approach was also suggested by Donna) who recommended,

"a greater level of collaboration between learner support and my particular subject area, and for learner support to be able to input into, positively input into, um what would be reasonable, what would be a reasonable adjustment."

\section{Evaluation and Limitations}

This study intended to seek a deeper understanding of the student participants' experiences in navigating dyslexia when newly identified at university. Whilst a wide range of materials were made available so that student-participants could create an artefact to represent their identity, the resources were limited. With other materials, students may have represented 
their dyslexia differently. Through induction, students had each been provided with a consistent overview of the nature of dyslexia and the importance of recognising both strengths and challenges. Whilst on the whole, this induction appeared to result in a positive alliance with dyslexia as a component of their identities, the ambiguity of how to define dyslexia individually remains a challenge for university studies.

\section{Conclusion and Recommendations}

Student-participants in this study did not feel that they were part of a homogenous group of students with dyslexia. In fact, on the whole, whilst students were generally positive about the fact that they had been identified with dyslexia at university, they did not see it as a defining characteristic of identity. Students enjoyed creating their artefacts, felt that doing this helped them to better understand how to describe their dyslexia to others and elected to photograph their creations so that they could use these to facilitate conversations with family, friends, lecturers and fellow students. In this instance, for these students, social identity theory did not appear to underpin the understandings they had developed about their dyslexias. Students did have a wide variety of experiences in terms of how they navigated their dyslexias from the point of screening to assessment to identification and support. This variety was reflective of their individual perspectives, actions and artefacts. Therefore a recommendation for practitioners within universities is that they consider how they approach the conversations about dyslexia and offer alternative ways for students to represent their experiences and understandings.

Inclusive practice requires collaboration between Dyslexia Support Tutors, Lecturers and Students to ensure a shared understanding of dyslexia exists; to facilitate individualised and appropriate interventions for students; and opportunities for students to articulate their identified needs without having to repeat these to each lecturer on multiple occasions. Students find that the identification or label of dyslexia can support them to begin to have constructive conversations about their needs; however, it emerged that the artefact could provide a useful visual aid to support their ability to differentiate general inclusive practice needs for dyslexia versus their individualised and specific needs. To build opportunities for reflexive conversations and metacognitive strategies, it may be beneficial for Students, Dyslexia Support Tutors and Lecturers to arrange a collaborative meeting whereby visual methods can be introduced to facilitate improved communication and collaboration between the three parties to improve the student experience.

There is scope to develop this research further by involving students from other universities and from different subject areas to consider whether or not the timing of dyslexia identification and the nature of the support that they receive at university shapes their selfunderstanding and experiences that inform their perceived identities. Expanding the development of the artefacts from the point of identification through to graduation would also provide a valuable insight into students' perceptions and understandings of their dyslexias over time. 
There are also opportunities to develop more specific inclusive practice recommendations through co-constructed research with students and to reflect on the possibility that evaluating strategies as individuals and as groups. However, the diversity of how dyslexia is experienced by individuals at university requires improved engagement with individual students. For this approach to be effective, it may be useful to co-create a dialogical toolkit with students to support lecturers and students to communicate differently about the individual nature of dyslexia and inclusion.

\section{References:}

Armstrong, D. and Humphrey, N. (2009) 'Reactions to a diagnosis of dyslexia among students entering further education: development of the 'resistance-accommodation' model', British Journal of Special Education, 36(2), pp.95-102.

British Educational Research Association (BERA) (2011) Ethical guidelines for educational research. Available at: https://www.bera.ac.uk/wp-content/uploads/2014/02/BERA-EthicalGuidelines-2011.pdf?noredirect=1 (Accessed: 30 January 2016).

Boyle C., (2013) 'Labelling in special education: Where do the benefits lie?' in Holliman, A. (ed.), Educational psychology: an international perspective, London: Routledge.

Brunswick, N. (2012) 'Dyslexia in UK higher education and employment an introduction and overview', in Brunswick, N. (ed.), Supporting dyslexic adults in higher education and the workplace, Chichester: John Wiley \& Sons, Ltd., pp.1-10.

Burden, R. (2005) Dyslexia \& self-concept seeking a dyslexic identity, London: Whurr Publishers.

Cameron, H. and Billington, T. (2015) 'The discursive construction of dyslexia by students in higher education as a moral and intellectual good', Disability \& Society, 30(8), pp.1225-1240.

Creswell, J.W. (2014) Research design qualitative, quantitative and mixed methods approaches. 4th edn., London: SAGE Publications Ltd.

Dale, M. and Taylor, B. (2001) 'How adult learners make sense of their dyslexia', Disability \& Society, 16(7), pp. 997-1008.

Denscombe, M. (2010) The good research guide for small-scale social research projects. 4th edn., Maidenhead: Open University Press.

Denzin, N.K. and Lincoln, Y.S. (2011) 'Introduction: the discipline and practice of qualitative research' in Denzin, N.K. and Lincoln, Y.S. (eds.) The SAGE handbook of qualitative research. London: SAGE Publications, Inc. pp.1-20. 
Dickman, E. (2017) 'Do we need a new definition of dyslexia?', Available at:

https://dyslexiaida.org/do-we-need-a-new-definition-of-dyslexia/, (Accessed: 2 April 2017).

Drever, E. (2006) Using semi-structured interviews in small-scale research a teacher's guide. Glasgow: SCRE Centre.

Eide, B.L. and Eide, F.F. (2011) The dyslexic advantage unlocking the hidden potential of the dyslexic brain, New York: Hay House.

Eide, F.F. (2016) Five stages of developing a positive dyslexic identity. Available: http://www.dyslexicadvantage.org/positive-dyslexic-identity/ (Accessed: 4 February 2016).

Goodley, D. (2017) Disability studies an interdisciplinary introduction, 2nd edn., London: SAGE Publications Ltd.

Henderson, P. (2017) 'Are there delays in reporting dyslexia in university learners? Experiences of university learning support staff', Journal of further and higher education, 41(1), pp.30-43.

International Dyslexia Association (2002) Definition of dyslexia. Available at: https://dyslexiaida.org/definition-of-dyslexia/ (Accessed: 14 January 2018).

Jamieson, C. and Morgan, E. (2008) Managing dyslexia at university: a resource for students, academic and support staff. Abingdon, Oxon: Routledge.

Jenkins, R. (2014) Social identity, Fourth edn., Abingdon, Oxon: Routledge.

Jensen, E. (2010) Different brains, different learners: how to reach the hard to reach, Second edn., Thousand Oaks, CA., USA: Corwin A SAGE Company.

Kannangara, C. S. (2015) 'From languishing dyslexia to thriving dyslexia: developing a new conceptual approach to working with people with dyslexia', Frontiers in Psychology, 6(1976).

Merriam, S.B. and Tisdell, E.J. (2016) Qualitative research a guide to design and implementation. 4th edn. San Francisco: Jossey-Bass.

Mitchell, C., Pithouse, K. and Molesane, R. (2009) 'The social self in self-study: author conversations', in Mitchell, C., Pithouse, K. and Molesane, R. (eds.) Making connections: selfstudy and social action, New York: Peter Lang Publishing, Inc., pp.11-24.

Nalavany, B.A., Carawan, L.W. and Sauber, S. (2013) 'Adults with dyslexia, an invisible disability: the mediational role of concealment on perceived family support and selfesteem', British Journal of Social Work, 45(2), pp.1-19.

Nicholson, R. (2015) Positive dyslexia, Sheffield: Rodin Books. 
Norum, K. (2008) 'Artifacts' in Given, L.M. (ed.), The SAGE encyclopedia of qualitative research methods. Available at: http://methods.sagepub.com/reference/sage-encycqualitative-research-methods/n15.xml (Accessed: 14 January 2018).

Pino, M. and Mortari, L. (2014) 'The inclusion of students with dyslexia in higher education: a systematic review using narrative synthesis', Dyslexia, 20 (4), pp.346-369.

Reid, G. (2016) Dyslexia a practitioner's handbook, Fifth edn., Chichester: John Wiley \& Sons, Ltd.

Riddick, B. (2000) 'An examination of the relationship between labelling and stigmatisation with special reference to dyslexia', Disability \& Society, 15(4), pp.653-667.

Savin-Baden, M. and Major, C.H. (2013) Qualitative research the essential guide to theory and practice. Abingdon, Oxon: Routledge.

Shaywitz, S.E. (2005) Overcoming dyslexia a new and complete science-based program for reading problems at any level. London: Vintage Books.

Smith, J.A., Flowers, P. and Larkin, M. (2009) Interpretative phenomenological analysis theory, method and research. London: SAGE Publications Ltd.

Smith, J.A. and Osborn, M. (2008) 'Interpretive phenomenological analysis', in Smith, J.A. (ed.), Qualitative Psychology a practical guide to research methods, Second edn., London: SAGE Publications Ltd., pp.53-80.

Solvang, P. (2007) 'Developing an ambivalence perspective on medical labelling in education: case dyslexia', International Studies in Sociology of Education, 17(1/2), pp. 79-94.

Swain, J. and French, S. (2000) 'Towards an affirmation model of disability', Disability \& Society. 15(4), pp.569-582.

Tajfel, H. (1978) 'Social categorisation, social identity and social comparison', in Tajfel, H. (ed.), Differentiation between social groups. London: Academic Press. pp.61-76.

Weinstein, R.S. (2002) Reaching higher: the power of expectations in schooling, Cambridge, MA: Harvard University Press.

West, T.G. (2009) In the mind's eye creative visual thinkers gifted dyslexics and the rise of visual technologies, Second edn., Amherst, New York: Prometheus Books. 